\title{
Scientific English in the EFL Classroom: Rethinking Our Pedagogies
}

\author{
Sara Djamàa \\ Department of English, El-Tarf University, El-Tarf, Algeria
}

\begin{abstract}
This paper critiques the prevailing approaches and methodologies Algerian faculty stick to when teaching scientific English to EFL university students. It urges a reformation of the existing pedagogies by offering practical considerations in the preparation of a challenging and engaging scientific English course. It further shares an innovative course outline that incorporates students' mini-lectures, role plays, Windows Live Movie Maker video projects, writing workshops, documentaries, guest speakers, and field trips and that uses games including crosswords, liar liar, scattegories, and flyswatter to enhance scientific vocabulary retention. A survey and interviews conducted with students report the overwhelming success of the course.
\end{abstract}

Index Terms - scientific English, EFL classroom, Algerian University, skills integration, sample course map, interactive activities

\section{INTRODUCTION}

Being the prevalent language of modern sciences makes it both a must and a necessity for EFL (English as a foreign Language) majors to seek a certain level of proficiency in scientific English if they are to achieve effective communicative skills and competencies that respond to international standards. Heading towards this goal, EFL students at El-Tarf University in Algeria take a mandatory course in scientific English to meet graduation requirements. Before the implementation of the LMD system ${ }^{1}$ in the Algerian universities, such course offerings were lodged merely in the subject-area departments where English constitutes a crucial component of scientific curricular but is not the primary subject of study. The departments of English, however, were limited to housing a theoretical course in ESP (English for Specific Purposes) with exclusion of such practical courses as "English for Science," "Business English" and others. Thus, as a university post-graduate who studied under the classical system ${ }^{2}$, I didn't have the opportunity to take a similar course in scientific English nor did my colleagues at El-Tarf University. In 2011, I was called on to give a course in scientific English for second year students for the first time in my career. I wouldn't hide that I was very worried about such a module attribution and the mission I was assigned seemed onerous to the extreme for I had no previous experience in teaching this subject and no clues about effective methods and pedagogies for tackling it. However, I had to go for it anyway for the course was left with no instructor. As a first reaction, I rushed to the staff room to beseech help from colleagues who already taught the course. I also conducted lengthy discussions and interviews with advanced level students who already took it. The results of my investigation reported a prevailing pedagogy that instructors stick to in teaching the subject throughout their courses. Attempting to objectively evaluate the existing approaches, I deduced that while the methodologies colleagues embrace might be effective and useful to a certain extent, they seemed to me antiquated, static, and lacking creativity -with respect to the efforts my colleagues deploy to provide a quality teaching-. Thus, I had to sit down and develop my own course content and my own approach to deliver it. Right from the very early class meetings, I was very surprised at the results. The course was a real success. In light of the encouraging results, I decided to share this outstanding experience for the benefit of my colleagues who are dedicated to the field of teaching English as a foreign language through the present paper which urges both an amendment and an enrichment of the existing pedagogies in teaching scientific English for EFL students. It unveils certain drawbacks, deficiencies, and misconceptions with regards to the existing instructional methods, on one hand, and offers key considerations in the preparation of a challenging and engaging scientific English course, on the other hand. While I hope the suggested guidelines might help individual instructors, they are by no means the "word" of scientific English instruction in the EFL classroom and remain open to constructive criticism.

\section{BEYOND READING: BROADENING THE SCOPE OF COURSE OBJECTIVES}

A typical scientific English lesson at El-Tarf University consists of exposing students to short extracts from scientific texts. The instructor invites the class to delve into a silent reading activity for a few minutes followed by a discussion of reading comprehension questions that target an evaluation of students' understanding of both the content knowledge

\footnotetext{
${ }^{1}$ LMD: It is an acronym for Licence-Master-Doctorat which correspond to the BA, Master's, and PhD degree. The LMD system has been integrated into the Algerian University in 2004 as part of the educational reforms that seek compliance with the American and European higher education standards.

2 The classical system: It is the Algerian higher education system that was superseded by the LMD system in 2004.
} 
and scientific terminology. The focus, then, shifts to grammar and language points that are specific to scientific discourse. The lesson at times concludes with a brief written expression assignment that prods students into paraphrasing and/or summarizing the text they have at hands. The prevailing method might fit those science majors whose primary need is to be able to read articles for research purposes and to write at least abstracts of their published papers in English. For the case of EFL majors, however, the adapted method shrinks the objectives of a Scientific English course to the mere preparation of students for the reading of print scientific discourse and the acquisition of a certain dose of scientific diction with little room for writing activities. While these are key sought after goals, they remain part of a whole and reflect a limited sight of what EFL students need to further grasp from English for Science courses. Indeed, after graduation, many EFL students end up working as affiliate professors in discipline-based departments where they are required to lecture in English in a particular area of expertise. As part of their academic activities in graduate schools and professional ones after, they take part in national and international conferences, seminars, and symposiums where they need to resort to spoken scientific discourse to skillfully present an academic paper or research findings before an audience. Working for national or multi-national companies such as SONATRACH, SONELGAS, ARSELORMITTAL, ASMIDAL, and others necessitates from the EFL student the skill of verbally reporting technical problems on the work ground, discussing the progress of a project with the manager, exposing the financial status of the company in an official meeting, etc. Our pedagogy disdains verbal practice of scientific English. Besides, in a scientific English course, our conception and use of scientific texts is limited to print scholarship from scientific journals, magazines, books, and internet ...etc. These text forms stand as the backbone of our instruction and the only means of presentation of scientific English while reading digital scientific texts including audio-recordings and documentary videos can be a very promising and rewarding material that offers an alternative way of acquiring scientific literacy in English. Students are more likely to gain better confidence to use scientific discourse in professional and non-professional situations if trained to consume and deconstruct spoken and written scientific discourse alike. Thus, Why not nudging them towards learning to listen to scientific English and listening to it to learn it? Indeed, a pedagogy that relies solely on reading material and a little bit of writing practice suggests that developing scientific English literate students is an exclusive rather than an inclusive process. It is my belief that a skillful amalgamation of the four language skills: Reading, writing, listening, and speaking is of paramount importance if we are to harvest the utmost benefit from the scientific English class.

\section{Beyond RAndom Selection of Course Content: Towards A Thoughtful Mapping Of THE Course RoAd}

After setting clear objectives that are likely to meet students' needs and remedy for their lacks, the next challenge is to create the course outline and build its content. In this respect, I decided to divide the course skeleton into what I chose to call "folders." Every folder bears the name of the target science and encompasses up to four files, each holding the name of the theme that constitutes the focal focus of study. By devoting a whole folder to a particular discipline, I drift away from the random unstructured selection of topics and from the routine practice of tackling merely one single text from a specific scientific field throughout the whole course such as exposing students to an excerpt on dialysis in a class as a sample of medical sciences texts and then teaching them another on atoms the following one. While giving more caliber to a given science before switching to another reduces the number of subjects students get to explore, the impracticality and impossibility of covering a myriad of scientific fields within a limited number of academic semesters remains a characteristic of both methods alike. Instead, by focusing on specific sciences, we are likely to gain the following:

1. Endow the course map with enough clarity and logic to guide students throughout their learning journey instead of a random selection of topics from differing scientific disciplines.

2. Help students acquire a fair load of scientific literacy in English in a given discipline.

3. Widen students' vocabulary repertoire in a particular scientific field.

4. Acquaint students with the characteristics and particularities of the scientific discourse of a specific science.

5. Initiating students for conducting research in English in the target scientific area.

The number of folders and files we chose to tackle is obviously tailored to the quantity of instruction devoted to the course -a 90 minutes class held once a week over 14 weeks. While we encourage our students to learn bits and pieces from every single scientific field with no exclusion or preference of one upon the other, the time frame remains a hurdle towards covering as much material as we want. Thus, we thought of privileging sciences that are very close to students' practical life and that would benefit and serve them even in their daily life. While it is quite common for a student to lead a conversation about a relative who has diabetes or blood pressure, a flu he caught, a throat infection, colon problems, and other health issues, it is rare to happen that he speaks about stars, planets, comets, nebulae, or galaxies. Although interesting, learning about astronomy might not be as useful and practical as learning about health sciences. A consideration of students' background and environment also is a key principle in folder selection. Most of our students, for instance, live in El Tarf, a rural state in Algeria famous for its fauna and flora as well as for El Kala national park which is recognized as a biosphere reserve by the UNESCO (Bougherara, 2010). Also, many families in this area breed animals including sheep, cows, chicken, and rabbits. This makes veterinary medicine and biology good targets for a scientific English course. In the event graduate students should be assigned teaching responsibilities in these academic departments, which are the oldest and largest in El-Tarf University, they will be prepared to sink their teeth in this 
academic adventure. Having these considerations in mind when planning one's course content, engenders high levels of motivation, interest, curiosity, and involvement from the part of students who will be grateful to us for an outstanding and effective scientific English course.

\section{From Simple to COMPlex Material: Towards a Gradual INCREASE OF THE DifFiculty LEVEL}

As we move from one folder to another and from one topic to another within the same folder, there is a hierarchy of difficulty to be respected so as to ensure that students digest well the material, harvest the utmost benefit from the course, and meet its objectives successfully. This complexity scale is with regards to the scientific notions and concepts as well as to the language and terminology we choose to introduce. In this respect, one important thing to bear in mind is that our classes comprise heterogeneous groups of students. Some of them were science majors in high school, hence, have a much more elaborate scientific knowledge and skills than groups of students who pursued a humanities or a foreign languages track. The latter, on the other hand, were more intensely exposed to the language and its structure and functions, although it is not always the case that they show better language skills than science majors. We need to cater for the differences in students' academic background and level of scientific literacy by starting with relatively simple yet challenging material and moving gradually towards a more complex content as the course progresses. With these key principles in mind, my course content for two semesters of study came out as follows:

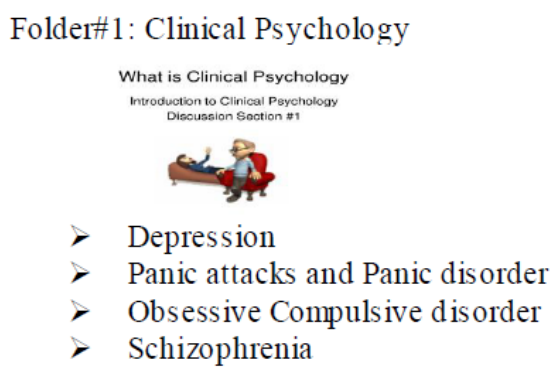

Folde1\#2: Medic ine

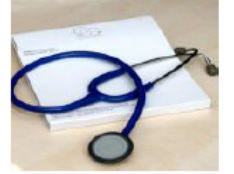

$>$ The respiratory System

$>$ Bronchitis

$>$ Asthma

$>$ Antibiotics (Augmentin)

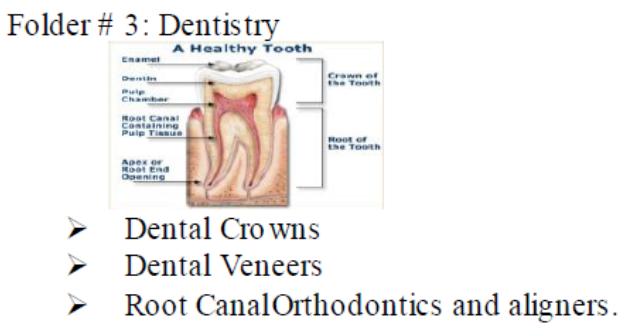

Folder \# 4: Veterinary Science

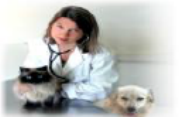

$>$ Cats common diseases

$>$ Dogs common diseases

$>$ Cesarean section in cattle

$>$ Artificial insemination

Folder \# 5: Biology

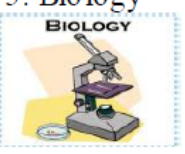

$>$ Otter

$>$ The Osprey (Pandion haliaetus)

$>$ Nuphar lutea (Yellow Water-lily)

> Eleocharis dulcis (The Chinese water chestnut)

Folder \# 6: Mathematics

$$
e^{i \pi}+\mathbf{1}=\mathbf{O}
$$$$
e^{i t}=\cos (\mathcal{U})+i \sin (\mathcal{U})
$$$$
r=\lim \left(1+\frac{1}{2} \ldots+\frac{1}{n}-\log (\mathrm{n})\right)
$$$$
V-E+F=2
$$

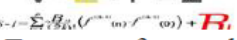

$>$ Types of numbers and basic Algebraic man ipulations.

$>$ Solving equations and diverse Algebraic problems

$>$ Basic geo metry concepts

> Solving problems of angles and triangles.

\section{VARying Classroom Activities, Course Materials and Assignments}

An English for Science course is a rich arena for introducing a myriad of classroom activities and assignments beyond the routine reading and writing practice and for using a wide range of material other than print texts retrieved from books or online. In this section, I will expose how I tackled parts of the course content I chose to teach. To begin with, the detailed course syllabus, particularly the course calendar section that cites the required and suggested readings along with the assignments' due dates and course events was the main reference document to help students get a sense of the course map and prepare for classes upfront. A glossary of 10 to 15 key scientific terms is handed over to students before treating each new file. It is often accompanied by a reading assignment with comprehension questions as a warm-up for the class. Every folder culminates by a project to be produced by groups of students. Given that classes are usually large, comprising up to 40 students, it would be unpractical to have them come up with individual projects because the time allotted to the course will not allow it. Hence, we decided to divide the class into 8 teams with each comprising up to 5 students who are expected to prepare the projects together.

A. Folder \#1: Clinical Psychology 
For the first two files in the opening folder, I relied on lecturing as the main method of instruction and delivered a regular clinical Psychology course as though I was teaching psychology majors. I used slide shows with charts, diagrams, and videos. To my surprise, the class turned into a crucible. Students' motivation, engagement and participation seemed to have highly peaked for the topics were remarkably appealing to them. The careful choice of topics relevant to students' interests was meant to help them grasp the terminology easily and to benefit them not only academically and professionally but in their own personal lives as well. Strikingly surprising was the fact that $65 \%$ of the students I was teaching suspected that they themselves might have been suffering from depression after shedding light on the depression topic. Many of them attempted at identifying the type of depression they might be having. Manel, a second year student, declares:

For years, I used to get so blue in winter, with significant decrease in appetite, weight loss and insomnia but it never occurred to my mind that this is a health condition associated with a type of depression that can be taken care of. Now I think I know: It is the nightmarish Seasonal Affective Disorder and I will try to seek help from a physician before this coming winter looks upon us.

Leila, a colleague at the Biology department and a second year student at the department of English certifies: “This lesson is a turning point in my whole life. I now come to realize that I am a real example of a depressed person. Thank you for enlightening my path!" The third file of the clinical psychology folder also took the form of a lecture. However, this time it was given by a team of five students who were assigned it right from the start of the semester. Each group member was responsible for a particular portion of the lecture. They assumed the responsibility of preparing the glossary of terms and providing the class with a reading assignment prior to their lecture. In class, they took roles in introducing the OCD (Obsessive Compulsive Disorder) definition, signs and symptoms, causes, categories, diagnosis and treatment. They enriched their lecture with pictures and videos they retrieved from internet. This was a good oral practice for them and an invaluable opportunity to prepare them for teaching such courses in the target subject departments. At the end of the lecture, students were given feedback by their classmates. The lecture was videotaped after getting students' consent. A copy of it was given to the concerned team members as a self-assessment tool along with a detailed written feedback from the part of the instructor and another was left at the disposal of the group delegate for the rest of the class to make copies of it and save it in the course portfolio as the first product of students in the scientific English course. The OCD file proved interesting to a considerable number of students. Hamida, declared:

I have a brother who, since his childhood, used to perform the ritual behavior of washing his hands excessively whenever he touches the door handle or finishes eating. He wastes a huge amount of time taking several baths a day to ensure he is clean. My mom's vain attempts to impede him from over cleaning his clean body make him very anxious, at times very aggressive. The family's perception was that this is part of his personality. He now is a university student. As he grew up, my parents' worries grew with him because he tends to waste more and more time everyday making sure he cleans up himself. After today's class, I will rush home to explain to my family that my brother's sufferings and my parents' worries are summarized in the OCD. God! Years of torture before the question mark is answered, and where? In a scientific English course!

Soumia had a hand up and in a short statement, she confessed in front of the whole class with tears in her eyes: “Today and only today, I came to realize why I lost the love of my life: I simply couldn't stop the CD of the OCD!" The last file "schizophrenia" that belongs to the first folder was treated through a couple of texts that students were assigned to read at home followed by a thematic, structural and grammatical in-class discussion with focus on the features of scientific discourse. We chose to wrap up the first folder by assigning a role play project to another group of five students. In this assignment, the group was required to tackle a new clinical psychology-related topic by performing a scene at the counselor's office. The group chose to shed light on Autism and Bulimia nervosa. Just like students lecturers, this group assigned two texts for the class to read and distributed a glossary of key terms prior to performing the play. One of the team members assumed the role of the psychologist, another incarnated the role of a parent with the third student representing the autistic child and displaying some of the autism symptoms in the play. Likewise, the remaining couple of students represented a bulimic adolescent girl accompanied by her mother. Both parents separately detailed to the counselor the symptoms their kids exhibit while the kids worked on displaying some of those symptoms to the audience and interacted with the psychologist to answer his/her questions. For both cases, the counselor diagnosed the illnesses, carried discussions with the parents on potential causes, case management recommendations, and suggested treatment plan. After the role play concluded, the floor was open for discussion. The team attempted to answer most of their classmates' questions to the best of their knowledge and then listened to their feedback. As we proceeded with the students' lecture, we got students' consent to videotape their role play, gave them a copy of the recording with a detailed written feedback and made another copy available to the class to keep in the course portfolio. It is worth mentioning that both the lecturing and role play activities are an alternative way to have mainly the studentperformers consume scientific texts, understand their underlying concepts and memorize the key vocabulary, an objective we used to seek achieving solely through engaging them in in-class reading and having them write summaries of texts.

\section{B. Folder\#2: Medicine}

The medicine folder opens by an anatomy of the respiratory system as the founding brick of the folder pile to pave the path for the study of bronchitis and asthma, two common respiratory diseases. With the principle of bringing 
something new to every class in mind, the discussion and analysis of the assigned readings was accompanied by charts and models of the respiratory tract and tertiary bronchi for both a healthy and sick person. I borrowed these for classroom use from a physician specialized in pulmonology who displays them in his office. The charts were big and to the course convenience, the terminology was written in English. I also used videos to make the sessions lively. We chose to use this material for our belief that it would be capturing to students' attention and interest and would result in a better understanding of the concepts imbedded in the texts. A medication leaflet is an authentic scientific text to take advantage of in this course and training students to read it is an important skill to acquaint them with when abroad or even in their country when encountering leaflets of imported medications written in English. For this purpose, I chose to introduce "Augmentin," an antibiotic prescribed for many illnesses inter alia lower respiratory tract infection. At the end of the folder, two groups of 5 students each were assigned the production of medical brochures presumably for the university's health center to display in the waiting room. One group chose to work on tuberculosis while the other opted for pneumonia. A third team of 5 members was assigned the translation of some sections of a medication leaflet along with its box and that will presumably be exported by the producing laboratory to an English speaking country. The team opted for Symbicort Turbuhaler, an inhaler produced in Sweden by AstraZeneca. The medication is abundantly available in the Algerian market and its leaflet is written both in Arabic, which is the native language of our students, and in French, the first foreign language studied in Algerian schools. Copies of the brochures, translated leaflet and medication box cover were handed over to students to read and add to the course portfolio.

\section{Folder \# 3: Dentistry}

This folder was treated mainly through audiovisual texts retrieved from internet. From the study of a number of videos, a group of students were asked to summarize the key content of the folder in a written form by producing themselves a written scientific text while taking into account the characteristics of scientific discourse. Another group of students was assigned a video project to animate the waiting room of a dentist's office. The group used Windows Live Movie Maker and opted for a synopsis of dental problems and their management including: cavities, gingivitis, bad breath, wisdom teeth, dentures, teeth whitening, brushing, flossing, fill ins, crowns, bridges, aesthetic dental surgery and others. A final group was requested to produce two posters to be posted at the dentist's office. For both projects, students used images, charts, diagrams and dental models.

\section{Folder \#4: Veterinary Science}

This folder was mostly taken care of by Dr. Kamel Miroud, a colleague majoring in veterinary sciences. A veteran of the veterinary school at El Tarf University and a graduate of royal veterinary college at the University of London, Dr. Miroud was formally invited to my course to give lectures on the two first files: cats and dogs common diseases. We invited him for we thought that having him in class as a guest speaker would endow the course with a creative flair and an interesting flavor. Students got exposed to a different approach to teaching scientific English as conducted in the department of the major and seemed to have appreciated the idea of breaking the routine by learning with a new teacher in presence of their own. Dr.Miroud's generosity extended to accepting my request to host students in the field to witness a cesarean section in a cow along with the artificial insemination process. The class stood fascinated by the spectacular procedure while listening to the explanation of Dr. Miroud in English and taking notes. Their retention of the terminology and understanding of the processes were strikingly remarkable and confirmed the magic of learning while doing. At the end of the folder, a group of students was asked to craft a scientific text on the cesarean section in cows while the other was assigned the same task for artificial insemination. The product was distributed to the class to read and keep in the course portfolio.

\section{E. Folder \# 5: Biology}

Lake Obeira in El-Kala National Park, listed as a wetland of international importance by the Ramsar Convention (The Ramsar Convention on Wetlands, no date), hosts the otter, a threatened species that is protected by the UNESCO. The Osprey, an endangered bird raptor species also dwells in the park and contributes to its faunistic richness. As you walk through the Park lakes or drive through El-Tarf national road, you cannot miss the eye catchy yellow-water lilies that cover the lakes' face while the underwater is rich by the rare aquatic plant named The Chinese water chestnut "Eleocharis dulcis." Located about 20 minutes away from El Tarf University, the fauna and flaura of El-kala National Park represented an appealing folder to tackle in the Scientific English course. Foci of the readings and audiovisual materials were on the scientific classification of selected fauna and flora (kingdom, phylum, class, order, family, and subfamily), nomenclature, life cycle, characteristics, habitat, nutrition, and threats. In addition to these aspects, the flora deserved a look at the potential pharmaceutical characteristics and culinary aspects. The biology folder culminated by two final projects: one asks a team to produce a tourists' guide to the Brabtia National park rare animal and plant species whereas the other assignment requires a different group to accomplish the same task in a documentary form. The two teams were asked to work in collaboration so that they introduce different species. The written guide displayed short ID cards of the Barbary stag (Cervus elaphus barbarus), also known as the Atlas deer, the spotted hyena (Crocuta crocuta), the caracal, the loggerhead sea turtle, the marbled duck or marbled teal (marmaronetta angustirostris), cedrus and myrtus (myrtle). The documentary, however, introduced bats, Monachus, the golden jackal (Canis aureus), the European Shag or Common Shag (Phalacrocorax aristotelis), the Purple Swamphen (Porphyrio porphyrio), the 
Ferruginous Duck, Cistus, rosmarinus officinalis and the bay laurel. As usual, the projects were distributed to the class to accumulate the course portfolio. This folder is particularly important for those students who will end up majoring in English for tourism in their final year of the BA degree.

\section{F. Folder \# 6: Mathematics}

While a Fulbright grantee to the United States of America, I considered applying for graduate schools to pursue my $\mathrm{PhD}$ studies. It was only when I went through the application process that I came to hear of the GRE test (Graduate Record Examination) for the first time and found myself in front of the challenging reality that I would need to study mathematics in English to be able to do well in the quantitative section of the exam. Hence, I joined the quantitative literacy Center at Hamilton College to help me prepare for the test. The mathematical notions we had to tackle were very basic to me. They centered mainly on middle school courses. However, the technical vocabulary was a real obstacle. I remember having failed to do a bunch of exercises in a sample test because I could not understand what such terms as "Isosceles" meant while I do perfectly know all of the geometrical rules and notions related to it in Arabic, my native language. As a former student of English, I would have appreciated having my ESP professor introduce us to basic mathematical concepts in English and initiate us for such an important test as the GRE. It is mainly why I chose to treat a folder on mathematics. I proceeded by teaching a regular mathematics class with problems that students worked in groups to solve. I concluded the folder by assigning sample quantitative sections of the GRE test to the whole class to work on at home. We then discussed the problems, corrected them and had students save their answers along with a copy of the answer key as part of the course portfolio. Besides, two groups of students were assigned the task of designing themselves mathematical problems and handing them to the remaining two groups to solve them as part of their project assignment.

\section{Language Games: Towards Boosting Technical Vocabulary Retention}

"Fill in the blanks in the following paragraph using the technical terms from the word bank provided to you below." This is the routine exercise teachers of English for Science give their students to check their memorization of the key scientific terminology. Scientific English courses are indeed a rich arena for introducing a myriad of activities to both boost and test students' retention of high technical vocabulary. To begin with, the classical fill in the blanks exercise can be done in an alternative way by prodding the class into listening to an audiovisual text while providing them with its script and requiring them to fill in the gaps with key words that are muted in the video. By doing so, students get trained to guess the high technical vocabulary in its context and practice spelling it themselves correctly rather than providing them with the terms. Besides, studies indicate that students learn better while having fun. In this respect, teaching games spice up the course and aid better vocabulary retention. Here are some possible games to take advantage of in English for Science courses. For Liar Liar and flyswatter, full credit is granted to a colleague of mine who shared them with me after a workshop held at the Middlebury at Mills intensive Arabic summer program in the context of teaching Arabic as a foreign language (AFL) and thereby inspired me to import them to the English for science classroom.

\section{A. Crosswords}

Our students are familiar with this game as they used to play it on the daily newspapers. Importing it to the class bridges the gap between school instruction and cultural practices that take place outside the classroom walls which is an invaluable motivation factor. The principle of the game is providing students with definitions or hints of high technical vocabulary terms and having them create a crossword out of them. They can work on it individually or in groups. The more difficult the clues are, the more challenging the game becomes.

\section{B. Scattegories}

Scattegories is an effective game to bolster the retention and review of the high technical vocabulary of a whole file. It consists of dividing students into pairs, providing them with a theme, and having them write as many scientific terms related to the target theme as they can. Students score a point for every distinguished answer and no points are due for similar responses.

\section{Liar Liar}

This game is to be played orally. The teacher divides the class into teams that sit in circles. In every team, a student is assigned the third person singular pronoun "it" and asked to stand out of the circle. The teacher asks all students to close their eyes so that he/she taps at the heads of three of them whose mission would be giving wrong answers to the questions the "it" student is to ask. The latter has to discover the liars in the group and once he/she succeeds in unveiling them, another student is picked up to be the one asking questions and filtering the wrong answers from the correct ones. This game helps students put into practice the vocabulary they learnt and test both their retention of it and their grasp of scientific knowledge in English (Magidow, no date).

\section{Taboo}


This game consists of having pairs of teams facing the board with a representative student from every team facing his/her team members i.e. with his/ her back facing the board to impede him from seeing what the teacher writes, draws, or posts on it. The team is given words, drawings or pictures and is assigned the task of guiding the student through explanations, definitions, or hints towards finding the term. The group members then take turns in representing their team by unveiling the technical terms provided by their teacher. The team that wins is the one with the largest number of students figuring out the words first.

\section{E. Flyswatter}

The teacher writes on the board a list of scattered technical terms. Pairs of teams have a representative student each. The teacher gives a definition or a descriptive statement of a technical term and the first student to hit the right word using a flyswatter scores a point for his team (Magidow, no date).

\section{EVIDENCE OF COURSE SUCCESS}

As a professor who designed and taught this course, I initially rated it as excellent, overwhelmingly successful. Students' tests, exams, projects, classroom participation, vocabulary retention, understanding of scientific notions, motivation, and engagement during the flow of the course were exceptionally outstanding. However, potential discrepancies might rise in some aspects of the course between my perception of it as an educator and their evaluation of it as learners. Hence, students' reaction to it is the word in assessing, and potentially absolutely confirming, its success. For this reason, we devised a survey of six categories which comprised a total of 42 Likert scale style items meant to assess students' evaluation of this scientific English course in comparison with previous courses they took. The two last questions of each category are somewhat summative of it. The survey was administered to a target pool of 134 students, ages 20 to 42 years, who constitute the whole population of second year students at the department of English in El-Tarf University and who all took my scientific English course. The participants were asked to voluntarily take part in anonymously answering the survey and were assured that no penalty is due for reluctance to contribute to the study and no extra credit will be given to respondents. Hard copies of the survey were distributed to them during a regular class session that took place three weeks before spring semester wrapped up. Extra copies were left with the delegate of every group in case some participants misplace their own copy of the survey. We made students aware that the day of the final exam, which was scheduled 5 weeks later, is the last possible chance for us to collect the respondents' answers.

Out of the 134 EFL students enrolled in second year, 53 returned the survey the following session i.e. a week later; 38 returned it two weeks after; 16 submitted it during the last session; 11 handed it to us immediately at the end of the final exam; while 16 didn't return it. This makes a total of 118 respondents.

The results of the survey (see Appendix B) revealed an overwhelming satisfaction with the course from different angles. Category 1 which targets an evaluation of structure-related elements yielded a very good rating with a weighted mean ranging from 4.5 to 4.73 . The overall evaluation of the structure of the course deserved a mean of 4.57 which is very satisfactory while the structure of previous ESP courses taken by students deserved a mean of 1.60 which is interpreted as dissatisfied. Category 2 is meant to evaluate the course content. Students expressed their extreme satisfaction with the relevance of the course content to their background, environment and practical life $(\mathrm{M}=4.12)$ as well as with the content originality, appeal, and engaging nature $(M=4.45)$. The hierarchy of difficulty in presenting the content deserved a relatively lower mean of 3.5 which is still interpreted as very satisfied in Likert scale. Overall, the relevance, appeal, and usefulness of the content of previously taken ESP courses yielded a mean of 1.52 which reflects the respondents' dissatisfaction while the content of the scientific English course was rated 4.20, which is a very good mean. Category 3 of the survey aims at evaluating the course activities, materials, and assignments. The lowest derived means in this category were $3.27<3.65<3.69<3.75<3.79$, attributed respectively to students' lectures, the writing workshops, models and pictures, the lecturing method, and at-home reading and writing assignments. While low compared to other items in category 3 , all these derived means fall within the range of a very satisfactory evaluation when referring to Likert scale interpretation. Students are used to most of these activities in other courses they take -with the exception of students' lectures-- which might be an explanation for why they rated them relatively lower than other items in this part of the survey. Course portfolio $(M=4.26)$, guest speakers $(M=4.28)$, audiovisual materials $(M$ =4.29), video-projects $(M=4.33)$, role-plays $(M=4.42)$, language games $(M=4.45)$, and field trips $(M=4.65)$ proved to be very appealing and useful for students. This might partly be due to their originality in the context in which they were introduced. The two concluding items in this category of the survey strive at comparing the evaluation of the activities, materials, and assignments of the scientific English course with those of previously taken ESP courses. While the latter yielded a dissatisfactory mean of 1.47 , the former deserved a very satisfactory mean of 4.41 . Items 27 through 35 in category 4 assess the achievement of course objectives which resulted in a lower mean of 4.09 and a higher one of 4.52 which all fall within a very good range. This confirms that the course met students' needs, necessities, and lacks that's why it deserved an overall mean of 4.24. Previously studied ESP courses, however, proved to have done poorly in guiding students towards achieving the sought after goals $(\mathrm{M}=1.60)$. Category 5 of the survey rates students' overall reaction to the course. ESP courses previously taken by students yielded a dissatisfactory mean of 1.60; the scientific English course deserved a very good mean of 4.41 when compared to other ESP courses and 4.37 when compared to 
other courses students took in the undergraduate curriculum. Finally, in category 6 which aims at rating students' concluding impression about the course, the respondents recommend the course approach and methodology to other ESP teachers with an excellent mean of 4.31 while they recommend it to other students of English with a slightly higher mean of 4.43. A peek at these results reveals the astounding success of the course.

Besides the survey, we randomly assigned 21 respondents i.e. 7 from each group to an interviewer, a colleague of us, to proceed with a 10-15 minutes interview (see Appendix $\mathrm{C}$ for questions). We avoided doing the interviews ourselves to maximize the honesty and credibility aspect of the answers. This would ensure students are not put in a situation where they would be giving only compliments and not discussing the cons of the course out of embarrassment or intimidation caused by the presence of the professor who was responsible for the course. The interviewees agreed upon a meeting time with the interviewer. Answers were recorded and the participants were guaranteed the anonymity of their contribution. Once the interviews were over, the interviewer delved into transcribing students' answers and into correcting the language without affecting the meaning. Then, she gave every student his coded transcript to review and check if he/she wants to add anything to his/her answers. After this, I received the final version of the transcribed interviews. Below are selected answers that summarize students' responses:

“An ESP course has never been this enjoyable and engaging for me. I found myself unconsciously internalizing a good deal of the course content without deliberate efforts. " Student E

In a culture where psychological and psychiatric conditions are a taboo, I was impressed by my classmates unveiling their sufferings and sharing them with us without complexes all along putting into practice the scientific knowledge and vocabulary we learnt. I think that was amazing, hard to imagine or expect before it did actually happen. I believe this is a testimony that the course definitely succeeded in motivating us and in increasing our engagement. Most importantly, it helped raise our awareness of certain things that have lifelong benefits beyond academia and the professional life. Student $\mathrm{K}$

To be honest, I used to constantly skip the ESP course as a freshman student. For me, it was dull. I can read a text at home, write the summary of it and answer the comprehension questions. Once in class, I expect discussing the text and doing interesting and original activities. Class time is precious. Are you kidding me! I come to the ESP class and spend most of it reading a text! This class, however, was a totally different story. When I first attended it, I could tell from the syllabus and the assignments that this course is setting high expectations and will potentially meet my needs and wants as well. And yes! It did. Student F

As we did expect, some students complained about the demanding nature of the course both time and material-wise:

"The course was interesting and motivating. However, the assigned activities, especially the projects, were time consuming. We would have loved it more if we had enough time to yield better quality work. Helas! Time was an obstacle." Students A

Our team members found the assignments very beneficial and enjoyable. We learnt a good deal and had a lot of fun. On the other hand, we spent about 10 days trying to find a friend or a relative who can lend us a camera to shoot our video project. This impeded us from working smoothly. Our word goes to the administration of the department which should provide us with the necessary equipment. Otherwise, it is unfair to have us waste such an amount of time and energy just to find the equipment we need. It would also be a big pity if we cancel such invaluable learning assignments and activities because of the lack of equipment. Besides, for such courses with innovative design and assignments, we shouldn't be expected to pay from our own pockets for materials that should normally be provided by the university. Come on! We are students and all we get is a stipend of 4000 Algerian Dinars every three months. The administration should consider this factor as well. Student C

Another obstacle confronted by students is expressed in the following statement:

The originality of the teaching methods and activities in this course was met by the reluctance of the surrounding environment and certain target services to collaborate with us in our attempt to seek help with information or authorization to pursue some research in certain sites. This culture is unfortunately absent and the university has to strive at ingraining it to facilitate the learning process for us. Student G.

\section{CONCLUSION}

It is high time to rethink our pedagogies in teaching Scientific English to EFL students. We need to remedy for our outlandishly unstructured courses by designing a well-woven syllabus based on logical principles and practical considerations that meet students' learning necessities and needs. Limiting the course agenda to the reading of printed scientific texts and the writing of relevant summaries is sabotaging students' growth. Instead, integrating the four language skills in addition to viewing maximizes their learning and engagement. Incorporating students' mini-lectures, role plays, Windows Live Movie Maker video projects, documentaries, recorded lectures, guest speakers, and field trips into the course is very rewarding. Writing workshops that train students in producing scientific texts themselves inter alia medical leaflets, posters, and brochures break the routine and classical activity of summarizing texts. Studying Science and memorizing high technical vocabulary while having fun is possible through the integration of language games such as crosswords, scattegories, Liar Liar, taboo, flyswatter and others. These suggestions are only a few amongst a myriad of others that we can come up with to endow our classes with a creative flair and help guide students 
towards achieving both the course objectives and career goals. Thus, Let us reflect on our teaching practices and methodologies; let us amend our current pedagogies!

\section{Appendix A. The ESP Course Evaluation Survey \\ El-Tarf University \\ Djamaà, $S$ \\ Spring 2012}

Dear respondents,

The present survey is meant to assess the effectiveness and success of the Scientific English course you took with professor Sara Djamaà throughout the 2011-2012 academic year. Your feedback is of great importance to us. Thus, we would really appreciate you devoting some of your precious time to completing it. The results we get will be released in scientific events and publications. The anonymity of the survey protects your identity and guarantees confidentiality. Please be advised that no penalty is due for reluctance to participate in this survey and no extra credit will be given to the respondents. Should you have any questions regarding the present survey, don't hesitate to contact Miss.Sara Djamaà via phone (o556619226) or e-mail dgimmah@yahoo.com

Thank you for your cooperation,

Sara Djamaà (Ph.D. student researcher at Badji Mokhtar-Annaba University)

Faculty of English at El-Tarf University

\section{Part A:}

This part is designed for statistical purposes. Please check the following boxes.

1. Respondent's ID:

2. Gender: Male $\bigcirc$ Female

3. Age:

\section{Part B:}

\section{Instructions for categories 1 and 2:}

For categories 1 and 2 below, indicate the degree of your agreement or disagreement abiding by the following scale:

1. Strongly disagree

2. Disagree

3. Neither

4. Agree

5. Strongly agree

\section{Category 1: Rating Course structure}

Scale

$\begin{array}{lllll}1 & 2 & 3 & 4 & 5\end{array}$

4. The course map was clear enough

5. I prefer to study a number of topics related to a particular discipline to the study of one topic from a bunch of sciences

6. ESP courses I took before were very well structured

7. Compared to former ESP courses I took, this scientific English course was more carefully woven and organized 
Category 2: Rating Course Content

Scale

$\begin{array}{lllll}1 & 2 & 3 & 4 & 5\end{array}$

8. The course content was relevant to my background, immediate environment, and practical life

9. The selected course content was original, appealing, and engaging

10. The course content respected a hierarchy of difficulty suitable to my language proficiency level and to my scientific knowledge background

11. In terms of content relevance, appeal, and usefulness, previous ESP courses were effective

12. Compared to other ESP courses I have taken, this course content is more effective

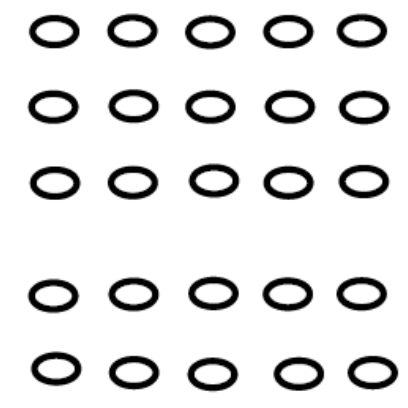

Instructions for category 3:

For category 3 below, indicate how you would rate the effectiveness and success of the course activities, materials, and assignments abiding by the following scale:
1. Not effective
2. Somewhat effective
3. Neutral
4. Effective
5. Very effective

\section{Category 3: Rating Course activities,} Materials, and Assignments

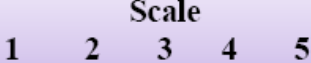

13. The lecturing method

14. Students' lectures

৪৪৪৪৪

15. At-home reading and writing assignments

16. The writing workshops

17. Audiovisual materials

18. Role-plays

19. Course portfolio

20. Course materials e.g., models, pictures, figures, and charts

21. Video projects

22. Guest speakers

23. Field trips

24. Language games

25. Overall, course activities, materials, and assignments of ESP courses I took before were

26. Overall, course activities, materials, and assignments of the scientific English course were

\section{Instructions for category 4 :}

For categories 4, indicate the degree of your agreement or disagreement abiding by the following scale:
1. Strongly disagree
2. Disagree
3. Neither
4. Agree
5. Strongly agree 
Category 4: Rating the Attainment of Course Objectives
$1 \quad 2 \begin{array}{llll}\text { Scale } & & & \\ & 2 & 4 & 5\end{array}$

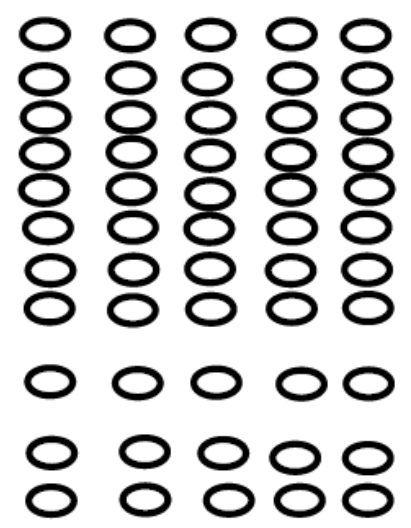

27. Course stirred my intellectual curiosity

28. Course increased my classroom participation and engagement

29. Course boosted my learning motivation

30. Course improved my reading of scientific texts

31. Course honed my skill of writing scientific texts

32. Course improved my skill of listening to scientific texts

33. Course improved my skill of speaking about scientific topics

34. Course deepened my understanding of scientific discourse and its characteristics

35. Course helped me acquire a considerable load of scientific terms in a range of disciplines

36. Previous ESP courses helped me achieve these objectives well

37. This course helped me achieve these objectives well

Instructions for category 5:

For category 5 below, indicate how you would rate this course:

1. Very poor

2. Poor

3. Average

4. Very good

5. Excellent

\section{Category 5: Rating Students' Overall Reaction to the Course}

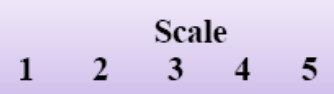

38. How would you rate previous ESP courses you have taken?

39. Compared to other ESP courses, I would rate this course as

40. Compared to other courses I have so far taken during my

Undergraduate studies, I would rate this course as

\section{৪৪০ঃ৪০}

Instructions for category 6 :

For category 6 below, indicate the extent to which you would recommend this course for other students of English and its approach to other ESP teachers using the following scale:

1. Not at all

2. To a certain extent

3. Not sure

4. strongly

5. very strongly

Category 6: Rating Students' Concluding Impression about the course

\begin{tabular}{llll}
\multicolumn{5}{c}{ Scale } & 2 & 3 & 4 & 5
\end{tabular}

00000

1. I recommend that other ESP professors adapt the approaches, methodologies, and activities used in this course

42. I recommend such a course for other students of English

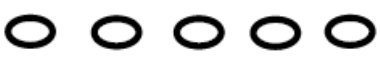

-End of Survey- 
ApPENDix B. Students' RATING OF THE SCIENTIFIC ENGLish COURSE

Results

\section{Category}

Survey Item

\section{Mean}

4. Clarity of the course map $\quad 4.73$

5. Preference for the study of a number of 4.5

Topics in a given discipline over the

Random selection of themes from

Different sciences

6. The structure of previously taken ESP courses

7. The structure of the Scientific English course

8. Relevance of the course content to students' background, immediate environment and practical life

9. Originality, appeal, and the engaging nature of the course content

10. The suitability of the course's hierarchy of Difficulty to students' level of scientific knowledge and language proficiency

11. Evaluation of the relevance, appeal, and usefulness of the content of previously taken ESP courses

12. Evaluation of the effectiveness of the Scientific English course content

13. The lecturing method $\quad 3.75$

14. Students' lectures $\quad 3.27$

15. At-home reading and writing assignments $\quad 3.79$

16. The writing workshops $\quad 3.65$

17. Audiovisual materials $\quad 4.29$

18. Role-plays $\quad 4.42$

19. Course portfolio $\quad 4.26$

20. Course materials e.g., models, pictures, figures, $\quad 3.69$ and charts

21. Video projects $\quad 4.33$

22. Guest speakers $\quad 4.28$

23. Field trips 4.65

24. Language games 4.45

25. Course activities, materials, and assignments of $\quad 1.47$

26. Course activities, materials, and assignments of the Scientific English course 
27. Arousing intellectual curiosity 4.11

28. Increasing classroom participation and 4.19 engagement

29. Boosting learning motivation 4.40

30. Improving reading of scientific texts 4.41

31. Honing the skill of writing scientific texts 4.09

32. improving the skill of listening to scientific texts $\quad 4.50$

33. Improving the skill of speaking about scientific topics 4.25

34. Deepening understanding of scientific discourse and 4.45 its characteristics

35. Acquainting students with a considerable load 4.52 of scientific terms in a range of disciplines

36. Previous ESP courses helped me achieve these $\quad 1.60$ objectives well

37. This course helped me achieve these objectives well $\quad 4.24$
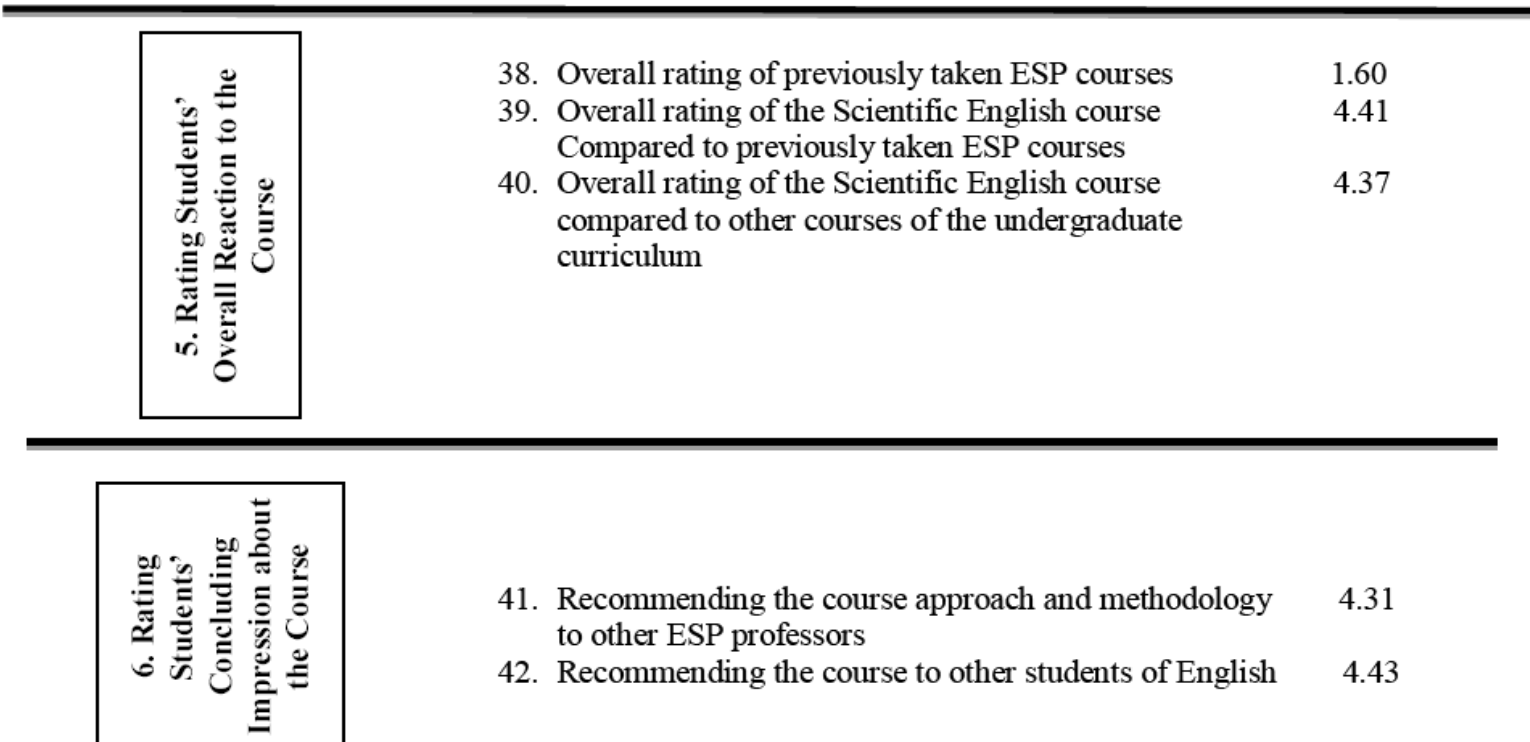

41. Recommending the course approach and methodology

4.31 to other ESP professors

42. Recommending the course to other students of English

\section{APPENDIX C. INTERVIEW QUESTIONS}

1. What are the pros of the scientific English course you took?

2. What are the cons of the scientific English course you took?

3 . What obstacles did you encounter in this course?

4. Do you have any comments you want to add about the course?

\section{ACKNOWLEDGEMENT}

A zillion thanks go to Dr. Kamel Miroud, a faculty member at the veterinary school of El-Tarf University who contributed to the success of the course by accepting to deliver two lectures and to host students in a field examination of the cesarean section and artificial insemination processes. We also acknowledge the help of our colleague Soumaya Aouaidjia who conducted interviews with students as well as the contribution of our colleague Alexander Magidow who served as a source of inspiration for certain language games.

\section{REFERENCES}

[1] Bougherara, A. (2010). Identification et suivi des paysages et de leur biodiversité dans la wilaya d'Eltarf (Algérie). Revue Télédétection 9. 3-4, 225-243. http://www.teledetection.net/upload/TELEDETECTION/pdf/Article5V1.pdf (accessed 23/11/2012).

[2] Magidow, A. (no date). Language teaching games. A blog for sharing language teaching games aimed at high school and college foreign language classrooms. http://languageteachinggames.blogspot.com/ (accessed 15/09/2012).

[3] The Ramsar Convention on Wetlands. (no date). The Ramsar list of wetlands of international importance. http://www.ramsar.org/cda/en/ramsar-documents-list/main/ramsar/1-31-218_4000_0__ (accessed 23/11/2012). 


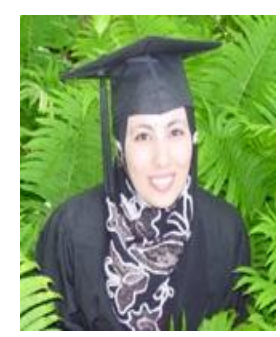

Sara Djamàa, was born in Annaba, Algeria on December 6, 1982. She earned her M.A. in TEFL (teaching English as a foreign language) at the University of Béjaia in Algeria in 2007 and her BA in English Language and Literature at Badji Mokhtar-Annaba University in 2004. Miss Djamàa was a Fulbright grantee to the United States of America in 2007 where she spent two years studying and doing research at Hamilton College, NY. She was an academic visitor to the Faculty of Education at Cambridge University in May 2010 where she spent a month doing research. Miss Djamàa also visited the department of English and related Literature at the University of York for a short term internship in May 2012. She currently is enrolled in a Ph.D. program at the University of Annaba in Algeria with a specialization in TEFL.

She served as Head of the English Department in El-Tarf University, El-Tarf, Algeria from 2009 to 2011 and is currently the President of the Scientific Committee of the department in addition to being a faculty member. She taught English composition, lectured on British and American literature, and gave courses in phonetics, ESP, scientific English, and oral expression at the University of Annaba, Béjaia, and El-Tarf for five years. She was an instructor of English at Djamile Sadki Ezzahaoui Middle School as well as Mohamed Boudiaf High School in Dar El-Beida, Algiers in 2005. Foci of her current and previous research interests include Teaching English for Specific Purposes, teaching methodologies and approaches, teacher education, syllabus design, learners' affective factors, film and literature, and technology in the EFL classroom.

Miss Djamàa is a member of the IATEFL (International Association of Teachers of English as a Foreign Language). 